\title{
Preface to the 30th Anniversary Volume: A Brief History of the Journal
}

\author{
Martel Zeldin ${ }^{1}$ - Alaa S. Abd-El-Aziz ${ }^{2}$ Songjun $\mathrm{Li}^{3}$
}

Published online: 21 November 2019

c) Springer Science+Business Media, LLC, part of Springer Nature 2019

Volume 30 is a landmark for the Journal of Inorganic and Organometallic Polymers and Materials. We have been publishing original research full-papers, shorter communications and review articles in the title area for almost three decades. How did this journal get started? In the spring of 1987, Dr. Martel Zeldin (MZ) was asked by the American Chemical Society's Divisions of Polymer Chemistry, Polymer Science and Engineering, and Inorganic Chemistry to organize a symposium on inorganic and organometallic polymers for the Fall 1989 National Meeting of the A.C.S. The timing seemed expedient given the accelerating pace of research activity and published research in a wide variety of areas that included polysiloxanes, polysilanes, polyphosphazenes, coordination polymers, and other relevant areas that were driven by useful applications as well as interesting and unusual technological properties. The multiday symposium was an outstanding success. As a result, the A.C.S. publications office suggested that a symposium series book on the topic be considered. The Petroleum Research Fund of A.C.S., the Office of Naval Research (ONR) and the abovenamed A.C.S Divisions encourage the production of such a tome and offered logistical and financial support to accomplish this task. Indeed, the book, "Inorganic and Organometallic Polymers, ACS Symposium 360," which was co-edited with Harry Allcock (Pennsylvania State University), Ken Wynne (ONR) and MZ, was published in 1988. The book

Martel Zeldin

mzeldin@ richmond.edu

Alaa S. Abd-El-Aziz

abdelaziz@upei.ca

Songjun Li

1sjchem@aliyun.com

1 Department of Chemistry, University of Richmond, Gottwald Science Center, C314, Richmond, VA 23173, USA

2 Department of Chemistry, University of Prince Edward Island, 550 University Avenue, Charlottetown, PE C1A 4P3, Canada

3 Research School of Polymeric Materials, Jiangsu University, Zhenjiang 212013, People's Republic of China too was quite successful with two printings. Shortly after the appearance of the book, MZ was approached by the Plenum Publishing Company of New York with the offer to sponsor a new journal in this research area. With the advice and encouragement from a number of distinguished inorganic and organometallic polymer scientists worldwide, the peerreviewed Journal of Inorganic and Organometallic Polymers was created as a quarterly periodical. The maiden issue of Volume 1 appeared in March of 1991 with nine research papers. Over the next decade, the journal had modest success. It was then clear that the journal needed to expand in order to prosper.

To help achieve this goal, Dr. Alaa S. Abd-El-Aziz joined our staff as a co-Editor-in-Chief in 2005. Since that time the journal has undergone significant changes. For example, it underwent a physical change from a small size to a large format (i.e., to $8.5^{\prime \prime} \times 11^{\prime \prime}$ ) with two-column printing. Soon thereafter, Plenum was merged with the Kluwer Publishing Company, which was subsequently purchased by Springer Nature, the current publisher. Throughout this period, there has been substantial acceleration in the number of submitted manuscripts (to more than 1200 in 2018), an increase in the number of published original research papers, shorter communications and topical reviews papers (283 in 2018; see Figure 1), an expansion of topics to include more inorganic and organometallic nano- and other macro-molecular materials, and a change in the title of the journal to reflect the areas of expansion; i.e., to the Journal of Inorganic and Organometallic Polymers and Materials (JIOPM).

In 2012 (Volume 22), the journal transitioned again from a quarterly to a bimonthly periodical to accommodate better the increased number of papers accepted for publication. During this period, we also expanded the Editorial Advisory Board (EAB) to include outstanding inorganic/materials scientists from the United States, Canada and abroad. We are still in the process of EAB expansion.

Handling over a thousand manuscripts annually has been a labor of love for the co-editors. To help with managing the manuscript load and to maintain high quality peer-review, we sought and this year (2019) appointed an associate editor, Dr. 


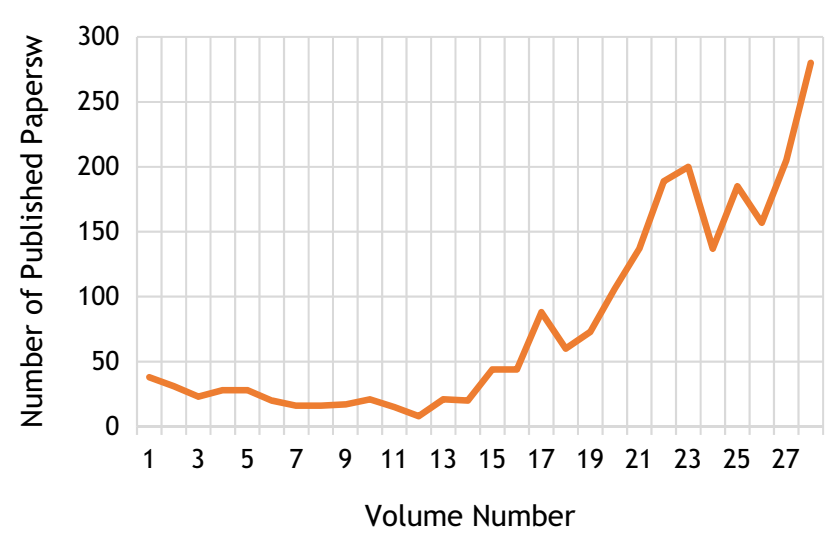

Fig. 1 Plot of the papers published per volume from 1991 through 2018

Songjun Li, a materials scientist from the Research School of Polymeric Materials \& Engineering at Jiangsu University.

It is important to emphasize that the journal has sustained a high quality of publications through the peer-review process. In fact, over the past several years, approximately $25 \%$ of the submitted manuscripts has been accepted for publication. Thus, it has become clear that, owing to the large number of submissions and positive reviews, it was necessary to increase the frequency of the issues published. Doing so in six issues per year has proven to be difficult. Therefore, effective in 2020, with Volume 30, JIPOM will become a monthly periodical.

What are our main goals for the next five-year period? First and foremost, we will strive to attract the highest quality manuscripts worldwide. To accomplish this goal, the editors and the EAB are reaching out to their research active colleagues to encourage manuscript submissions. Our second main objective is to complement the current EAB with more young, active, and mid-career scientists so the journal can remain at the cutting edge of research dissemination in the title areas. Thirdly, and perhaps most difficult, is to identify the best qualified peer-reviewers to ensure that the papers we publish have been suitably screened for novelty of research results and quality of research methodology. One measure of our success in these endeavors will be an increase in the Journal's Impact Factor, which we carefully monitor annually.

The editors want to thank our EAB for their continuing support, and all the reviewers for their careful scrutiny in evaluating the novelty, value and significance of the submitted manuscripts. Without their help, the journal could not thrive.

We also wish to acknowledge all our colleagues at Springer Nature who have supported this journal in many ways and enthusiastically contributed to our success. The essence of scientific research is to learn from nature and to solve complicated scientific problems. Thus, it is our wish that the ongoing expansion of the JIOPM from a bimonthly to monthly periodical will better promote the development of the field of inorganic and organometallic polymers and materials.

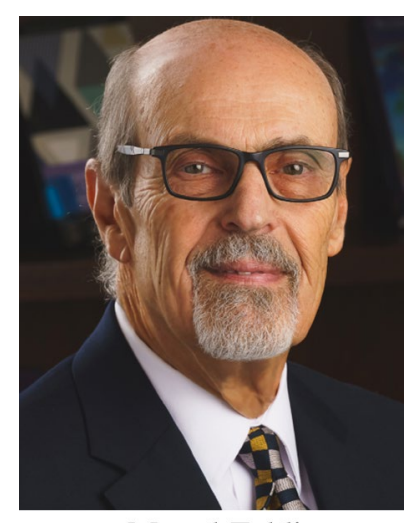

Martel Zeldin

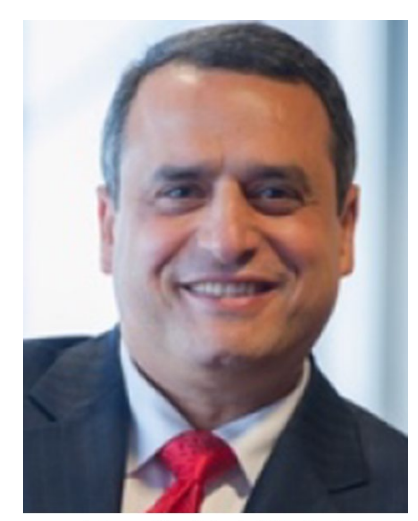

Alaa S. Abd-El-Aziz

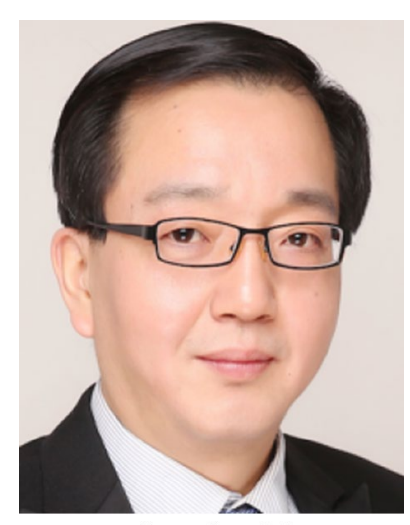

Songjun Li

Publisher's Note Springer Nature remains neutral with regard to jurisdictional claims in published maps and institutional affiliations. 